\title{
Scaffolding the Online Peer-support Experience: Novice Supporters' Strategies and Challenges
}

\author{
TIANYING CHEN, Carnegie Mellon University, USA \\ KRISTY ZHANG, Carnegie Mellon University, USA \\ ROBERT KRAUT, Carnegie Mellon University, USA \\ LAURA DABBISH, Carnegie Mellon University, USA
}

\begin{abstract}
People with mental distress are increasingly turning to one-to-one synchronous communication websites to receive peer support from other members. Though some research has identified benefits and challenges of online peer-support, there is a limited understanding of how to best prepare and scaffold for untrained peer supporters as they attempt to become skillful in an online setting. We recruited 30 (15 pairs) participants to engage in an online support conversation about procrastination problems, gave one member of each pair minimal training in the principles and strategies of motivational interviewing, and used interviews and conversation transcripts to examine challenges novice helpers faced when providing support and learning new conversational skills. We presented the helpers with two conversation goals to achieve with the conversation: building understanding, and promoting readiness for change. The research identified the common strategies the helpers used to achieve these goals and the challenges they faced. We also discuss theoretical and design implications for platform designers to better scaffold this experience.
\end{abstract}

CCS Concepts: $\bullet$ Human-centered computing $\rightarrow$ Empirical studies in collaborative and social computing; • Applied computing $\rightarrow$ Psychology.

Additional Key Words and Phrases: peer support, online community, grounded theory

ACM Reference Format:

Tianying Chen, Kristy Zhang, Robert Kraut, and Laura Dabbish. 2021. Scaffolding the Online Peer-support Experience: Novice Supporters' Strategies and Challenges. Proc. ACM Hum.-Comput. Interact. 5, CSCW2, Article 366 (October 2021), 30 pages. https://doi.org/10.1145/3479510

\section{INTRODUCTION}

Almost half of the U.S. population will experience a mental disorder in their lifetime [23]. Only about $34-45 \%$ of individuals, however, actually seek the help they need [23]. Commonly cited barriers to help-seeking include: living in a rural area, self- and perceived-stigmatization to seeking help for mental health problems, holding negative attitudes towards seeking help, or having negative past experiences with mental health professionals [23]. With the development of novel technologies connecting people online, people can now turn to online support groups, online self-help programs, and psychologists offering counseling via email, chat, webcam, etc. These services are expected to expand and increase [23]. People are also welcoming platform-based peer support and using these services as an alternative to professional therapy [4]. One example of a platform-based peer-support

Authors' addresses: Tianying Chen, tianyinc@andrew.cmu.edu, Carnegie Mellon University, Pittsburgh, Pennsylvania, USA; Kristy Zhang, kristyz@andrew.cmu.edu, Carnegie Mellon University, Pittsburgh, Pennsylvania, USA; Robert Kraut, kraut@ andrew.cmu.edu, Carnegie Mellon University, Pittsburgh, Pennsylvania, USA; Laura Dabbish, dabbish@andrew.cmu.edu, Carnegie Mellon University, Pittsburgh, Pennsylvania, USA.

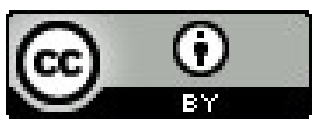

This work is licensed under a Creative Commons Attribution International 4.0 License.

(C) 2021 Copyright held by the owner/author(s).

2573-0142/2021/10-ART366. https://doi.org/10.1145/3479510

Proc. ACM Hum.-Comput. Interact., Vol. 5, No. CSCW2, Article 366. Publication date: October 2021. 
services is 7 Cups of Tea, in which volunteers provide free 24/7 emotional support to members through a web or app-based messaging system enable these individuals to have private support conversations with their peers $[8,51]$. Research has shown positive outcomes from peer-assisted interventions, such as emotional support and well-being. Users have also indicated that online peer emotional support is just as helpful as psychotherapy [9]. Platform-based peer support have offered benefits in coping, identity re-evaluation, and empowerment [76]. Compared with support provided by health professionals, the peer support provided through these online platforms focuses more on searching for meaning, identifying and meeting the client's needs, and serving as a role model [2]. However, research has also pointed out the fact that when used alone, platform-based peer support have produced disappointing outcomes [28]. This lack of high-quality peer support platforms that can provide supporters with proper training and conversation skills implies an urgent necessity for scaffolding a platform that can help peer-support providers conduct more effective conversations [52].

There are two major challenges to the effectiveness and sustainability of these peer-support platforms: volunteer turnover and lack of professional training are well reported by prior literature $[10,48,50,65]$. However, these findings tend to focus on a macro-level analysis of challenges that these platforms face which do not reveal the underlying causes on the supporter's individual level that might be caused by the lack of focus on novice supporters for volunteer retention and skill development. This is demonstrated by a limited understanding on the experience of untrained peer volunteers and the process of how they develop the skills necessary to become successful helpers in an online setting.

At the same time, peer-support and counseling services conducted through text-based platforms have not been thoroughly investigated by prior research. Even though there are a relatively small number of studies exist on this topic [26,32], no research study to date has reported difficulty specifically related to using real-time text-based platforms for the counselor. To investigate these problems, we conducted an interview study with 15 novice helper-client pairs in a controlled environment. By analyzing both the interviews as well as the conversation transcripts between the helper and the client, we present a model how novice helpers navigate through a peer-support conversation on a text-based support platform and discuss the strategies they use as well as challenges they face.

\section{BACKGROUND}

\subsection{Online therapy}

Online professional mental health services such as teletherapy allow clients to feel more comfortable and may be more suitable for young individuals compared to traditional in-person therapy [24, 75]. For example, the removal of face-to-face interaction may actually increase self-disclosure and honesty in clients [5]. This may be due to the disinhibition effect in which some people self-disclose or act out more frequently or intensely than they would in person when online [69]. Anonymity may allow people to feel less vulnerable about sharing personal details and may reduce the stigma or embarrassment of physically being seen to seek help [23]. Furthermore, characteristics of online counseling such as anonymity, asynchronicity, and accessibility enhance adolescents' control over self-presentation and self-disclosure, and this enhanced controllability is the reason why the Internet is so attractive to adolescents [77]. Mental disorders are most prevalent amongst young adults, but young adults are the least likely to seek help [23]. Online therapy is an opportunity to address this barrier. Compared to face-to-face counseling, online counseling has shown similar impact on and therapeutic alliance with clients [57]. However, there are also challenges in regards to online counseling. With the lack of face-to-face visibility, nonverbal cues such as body language 
and facial expressions as well as vocal qualities cannot be transmitted or detected [23]. There are also many different skills related to counselling that are specific to use in the virtual modality, such as tracking nonverbal cues, imagining the client's presence, written communication, etc. $[19,48,74]$

2.1.1 Online peer-support services. Peer-support service has existed for a long time $[18,39,47,67$, 79]. As part of a national movement on mental health systems, a multitude of opportunities quickly multiplied across the country in the early 1990s for providing and receiving peer support within the mental health system in the United States [20]. With the spread of the Internet, support groups have also moved to the online space $[4,49]$. More recently, websites such as 7 cups.com provide private one-on-one peer-support services through an anonymous chat interface [51]. Peer-support provide various benefits to participants. Mead et al. [39] describes peer support as:

"Peer support is a system of giving and receiving help founded on key principles of respect, shared responsibility, and mutual agreement of what is helpful. It is about understanding another's situation empathically through the shared experience of emotional and psychological pain (p.135)."

Peer providers having shared experiences with the individuals they are helping serve as excellent role models and are better at relating to them $[39,40]$. Also, those who help other peers also gain from this experience as much as they give, and those receiving help were inspired to be like the peer volunteers who were farther along in their recovery [3, 67]). Prior literature has also identified benefits of online peer-support services. These support services are often used in conjunction with traditional therapy. For instance, Griffiths et al. [29] found that online support groups when used in conjunction with traditional therapy is effective. Moreover, online peer-support services are reported by users to fulfill their needs outside of therapy, including emotional support and self-discovery [10]. In the mean time, compared to traditional therapy that is more focused on finding solutions, peer support focuses more on searching for meaning, identifying and meeting the client's needs, and serving as a role model $[2,39]$. We do recognize that high-quality and large randomized control clinical trials are not yet very common to clinically demonstrate the effectiveness of peer-support services. Nonetheless, considering the recency of online peer-support services [4], all the preliminary evidence point to a very promising direction for further efforts in research and design.

2.1.2 Challenges to online peer-support services. Despite the promising direction provided by online-peer support services, research has shown certain challenges that these services face. Prior research has shown a lack of training in online peer-supporters [65]. Due to the differences in online versus in-person interactions, it is crucial for helpers to receive resources and training to navigate differences from face-to-face therapy and develop a strong therapeutic alliance with their clients. However, counsellors question the adequacy of training for traditional psychotherapy and observed that there is a dearth in training for online counselling [48]. Peers have shown a strong interest in learning peer counseling skills online to provide each other with emotional support-signaling an important unmet demand for guidance [52]. However, few efforts scaffold peer supporters to use best practices, such as effective principles of talk therapy, in online settings [52]. It is important to design guidance for helpers that is useful, appropriate, and effective [52].

Inadequate training also has an impact on volunteer turnover $[9,50,65]$. Studies of volunteer retention have determined that the first six months of volunteers' experience is critical toward their retention, as the greatest loss of volunteers occurs during this period [65]. One of the most frequent motivations for discontinuing volunteer service is inadequate training [65]. Training for volunteers is overlooked when agencies view their volunteers as employed professionals who are just giving 
of their spare time [65]. Training not only helps volunteers work better, but also helps to motivate them to donate time. Experience is the best way for volunteers to learn and stay motivated [65].

Aside from inadequate training, it is also not clear how skills are actually developed in peersupporters after receiving the training as well as the difficulty the helpers might have developing these skills [55]. Even though this process is not clear, there is existing literature on how professional therapists learn and gain skills that could serve as a basis to understand this process in amateur helpers. This process is broken down into three important components: first, therapists must learn the factual skills of successful therapy sessions. Second, they must learn how and when to apply these skills. Last, therapists must reflect on their experiences and be able to apply declarative and procedural knowledge to new situations [12]. Current research has demonstrated that lack of training is evident. These results focus on the declarative knowledge of what the supporters learned, but not what they do with the knowledge and how they translate the knowledge into practice, as well as the challenges they face during this process. We try to answer these questions with our study by specifically providing the helpers with training on motivational interviewing skills similar to what current peer-support platforms provide and understand the challenges they have utilizing these skills.

\subsection{Motivational interviewing}

Motivational interviewing (MI) is a counseling style first developed mainly to target at health behavior change, such as smoking cessation [33, 41, 43, 59,61]. A large number of clinical studies have demonstrated the effectiveness of this intervention in producing positive clinical outcomes for inducing health behavior change [42]. It has also been adapted to other topics and used as a general talk-therapy skill used in conjunction with other evidence-based clinical interventions such as cognitive behavioral therapy [60]. The MI approach assumes clients want to change some behavior, know the type of change that would be best for them and their barriers to implementing this. The helper's role is to extract this information from the client and have them talk themselves into change [61]. In comparison, most common therapy approaches, such as cognitive behavior therapy, assumes a deficiency model where psychological disturbances come from a lack of skill in certain areas and the therapist's role is to instill and teach these skills to the client [25]. This model, compared to MI, requires clinical expertise to responsibly find appropriate solution for the clients. As prior literature suggested, there has not been effort made in scaffolding peer supporters to use effective principles of talk therapy in online settings [52]. Given the premises of $\mathrm{MI}$ in an online environment where both parties are most likely amateurs, we believe the conversation skills from MI sets a strong foundation for introducing best practices to novice as well as experienced supporters. The idea of MI by its developers supports this notion: they frame MI as a "way of talking" instead of a specific clinical intervention [33, 38,61] and recommend it to be used in conjunction with other techniques and in more than just clinical situations [22,62]. This versatility provides strong support for it to be introduced as evidence-based conversation skills for online peer-support conversations.

It is also important to clarify that in our study we did not aim to teach the participants the systematic way of conducting MI, nor did we expect the participants to become masters of MI. Instead, we selected useful and proven effective conversation skills from the vast domain of motivational interviewing in order to facilitate the conversations and help supporters to provide more effective conversations. More specifically, the three skills that we provided the helpers with were: 1. reflection: reflect and interpret what the client says in one's own words, 2 . open-ended questions: asking open-ended questions that cannot be answered with a "yes" or "no", and 3. affirmations: identifying client's strength and effort they are making towards the targeted change from the skills in MI [59]. These skills were considered "tools" to use to facilitate the conversation in

Proc. ACM Hum.-Comput. Interact., Vol. 5, No. CSCW2, Article 366. Publication date: October 2021. 
order to move the conversations towards change. By providing MI skills training to the participants, we try to fill the gap in previous research on the lack of scaffolding in effective conversation skills for peer supporters. We also aim to understand the challenges that the supporters have in applying these skills in real support conversations. In summary, we aim to answer the following two questions with our research:

RQ1: What are the strategies that novices employ to hold a peer-support conversation?

RQ2: What challenges do novices have when holding a peer-support conversation after receiving typical amateur support training?

Even though there have been a multitude of research on MI training as well as its outcome, most of the research focuses on quantitative outcomes of trainee competency and big-picture barriers and seldom investigate qualitatively in depth on difficulties acquiring new skills and skill-focused challenges, or what strategies trainees adopt to cope with the transition into a more MI-consistent style of conversations. We contribute to the literature by providing a theoretical structure to understand the process and strategies amateur novice peer-supporters employ to transition into skill-based support conversations and barriers they face with providing these conversations. With these insights, we provide design implications and suggestions for scaffolding more effective online peer-support conversation services.

\section{METHODS}

In order to answer the research questions, we conducted an interview study with 30 participants to understand how naive helpers are able to incorporate training into their support interactions with a client. In this study, we produced a controlled environment where participants who did not have prior experience with peer-support were recruited specifically for the study purpose and we limited the support conversation topic to procrastination. Prior literature that focused on understanding problems that peer-supporters face tend to focus on the recall of distant events from the supporters. As we try to understand the process of skill development and difficulty that novice supporters face, it is unreliable to rely on recall of distant experiences from experienced supporters. In our study, participants were immediately asked to report on their experience after the conversation so we could collect first-hand information that is most accurately reflective of their initial experience. Moreover, to maintain the consistency of the topic and reduce variance between different supporters, we chose a topic that is commonly experienced, not emotionally traumatizing, as well as similar to the goal of health behavior change that MI was developed for. In the following sections, participants in the supporting role are referred to as helpers.

\subsection{Procedures}

Thirty participants were recruited through the Center for Behavioral and Decision Research participant pool at Carnegie Mellon University for a study about procrastination. The 30 participants joined the study in 15 pairs. In each session, the participants were randomly assigned to be either the helper or the client. The helpers were asked to help the client with the procrastination problems, and the client were instructed to share details about their procrastination issues. The helpers also received training on motivational interviewing skills derived from training materials that 7cups.com uses to introduce new helpers to active listening skills. The pair were then asked to have a text-based conversation in a private channel for one hour following the instructions. After the conversation, the helper was given an interview about their experience, and the client was given an open-response questionnaire asking them about their experience in the session. This study was reviewed and approved by the university's Institutional Review Board. All participants consented 
to participate in the study, to have their voice recorded for the interview, and to have the interview transcript and helper-client conversation analyzed.

\subsection{Training materials}

With the recommended motivational interviewing practices discussed in the previous section in mind, we designed two goals for the helpers aligned with best practices taught in motivational interviewing, discussed in the previous section, in order to give the helpers a clear direction to go for their conversation: 1) building understanding, and 2) promoting readiness for change. We included two instructions with more details to clarify these two goals. For building understanding, the helpers were instructed to 1) understand the problem that the client is going through and their experience, and 2) focus on the client's experience and make them feel heard. For promoting readiness for change, the helpers were instructed to 1) agree with the other participant on what they want to achieve through this conversation, and 2) try to help them clarify their thoughts on how they plan to solve the problem.

To facilitate helpers achieve the conversation goals, they were also given reading materials on appropriate motivational interviewing skills: open-ended questions, reflections, and affirmations We decided to adopt the training materials developed by 7 cups.com for these skills in order to recreate a more realistic scenario for the helper training. 7cups.com provides its helpers training using a simplified version of these three skills. In the training, each skill starts with a brief summary explaining what the skill is, then followed with some tips on how to do the skills and things to watch out for, as well as examples on what they could say for each skill. For instance, below is some excerpts from the training for the affirmation skill:

Sample summary: We all have strengths and it feels wonderful when others notice them. Let the person know you see them as strong, powerful and capable. This helps to build their self-esteem and confidence.

Sample tip: Notice anything the person has done well! It could be passing a test, finding a new job, or simply getting through the day when their mood was very low.

Sample example: I appreciate that you reached out to speak with me.

We explained to clients that throughout the process they should aim to clarify the goal of the conversation, share their problem, have a deeper understanding of their problem, and identify potential ways of solve their problems together with the helper.

\subsection{Interviews and analysis}

In order to comprehend and capture the richness and depth of the helping experiences, we used semistructured interviews to understand the helpers' experience. The interviews happened immediately after the conversation between the helper and client finished, and were structured in a way that resembles a post-interaction think-aloud protocol. During the conversation, the researcher took notes of meaningful moments and asked about the thought process behind these moments in the interview. The helpers were asked to bring up their conversation interface and walk the experiment process through the conversation and the rationales for each response. Helpers were also asked to identify meaningful moments they felt either facilitated or hindered the conversation. These questions took the forms of "Please look back at the conversation and identify a timestamp where you thought was a meaningful moment. Could you walk me through what happened?" The researcher also asked general questions about their experience such as "What was the most challenging aspect of the experience?" 
The data was analyzed with the ATLAS.ti software. We analyzed the interview data in conjunction with the exchanges between the helper and the client. We also used the questionnaire that was provided to the client after the session to assist the identification of helper challenges. For the sections in the interview where the helper explained a moment from the exchanges with the client, the sections were put into a comment next to the interview transcript. For the analysis process, we employed a grounded-theory approach [68]. Using the theoretical sampling process, the researcher annotated and open-coded all the transcripts as the interviews were being conducted and refined the interview protocol in order to further discover new interesting themes that emerge in the interviews. This process continued until no new themes were discovered. The researchers then related and categorized the codes through the axial coding process in order to generate a small subset of themes. In the following sections, we report our findings in relation to the two goals and the three skills represented in the previous section. Participants with an "h" prefix such as H1 denotes the helper in pair 1 , and "c" the client. The number signifies the pair number. The text conversation exchanges between helpers and clients were kept with the original typos and missing punctuation. For the interview transcripts, we lightly edited interviewee's quotes for readability. We summarized the findings related to the conversation goals in Figure 1. In the following sections, we discuss our results in relation to the two conversation goals: building understanding, and promoting readiness for change. In reporting our findings, we first discuss the common strategies that helpers used to achieve the assigned conversation goals, then present the difficulties they faced associated with each strategy.

\section{BUILDING UNDERSTANDING}

We identified two components that the helpers aimed to achieve for this conversation goal: analyzing the problem, and building rapport. In order to successfully build an understanding of the client's situation, the helpers first needed to analyze the problem and understand the details and nuances of the situation the client was in. At the same time, it was also important for the helpers to build a rapport with the client in order for the client to open up and share about their experience.

\subsection{Subgoal: Analyze the problem}

4.1.1 Strategy: Help clients open up with reflection. The most common strategy that helpers used in order to analyze the problem that the client was facing was using reflections, that is rephrasing the client's statement with some of the helper's own interpretation in order to advance the conversation. In using reflections, helpers report that they want to show that they understand the client's issue as well as try to help the clients open up about their experience.

C7: "yeah that's true! also i actually accomplish so many cool things when i'm procrastinating!!"

H7: "life is not a the destination, it's the journey" lol"

C7: "like working on music or reading comics or making a house for my cat .. something unnecessary but fun. yeah i wish my whole life was just procrastination. it would be so fun lol i hate dealing with real shit"

H7: "there seems to be a big contrast between your seeming frustration with establishing long-term goals versus the joy you express in the things you do during the procrastination"

C7: "yeah.... it would be great if i could somehow transfer that... like you said a freelance career would be ideal... if it wasn't so unrealistic / impossible to manage financially... i think it's the long term commitment that i really have a problem with" 

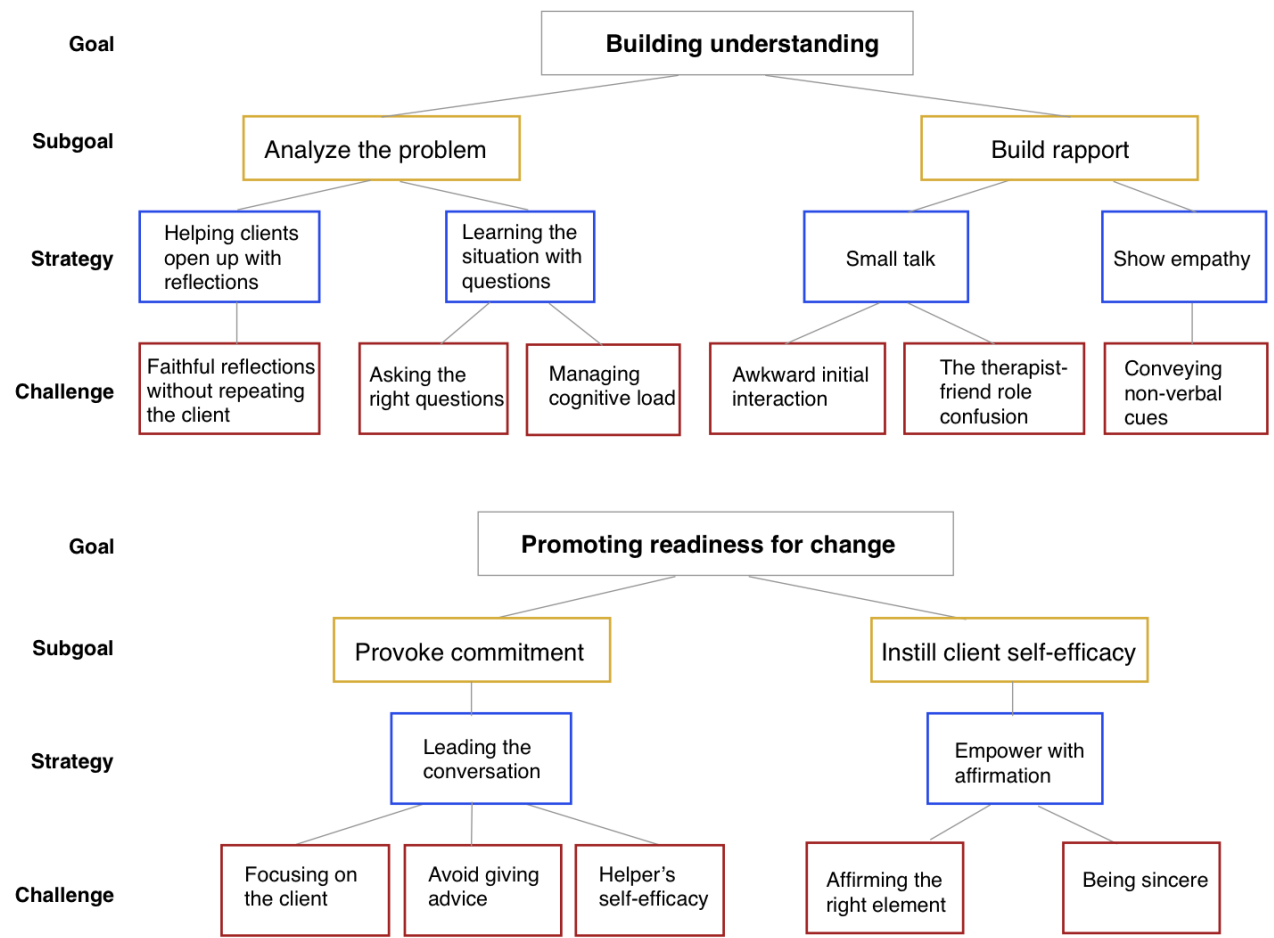

Fig. 1. Model of Conversation goal, strategies, and challenges

In this example, $\mathrm{H} 7$ used two reflections that not only demonstrated their understanding, but also pointed out the important information buried in C7's statement, which was a problem with long-term commitments. This lead to C7 opening up more about their problem, filling in even more details, and in the end agreeing with the helper that long-term commitment was indeed a problem.

4.1.2 Challenge. In motivational interviewing training, an interviewer's proper usage of reflections is a common criterion for evaluating the quality of their MI skills [45, 59]. Providing reflections is not commonly something that participants are used to in natural conversations. For some people it bordered on not paying attention because a reflection does not require the addition of new information from the other interlocutor but instead is a rephrase on an already existing piece of information. The most common challenge reported by eight participant was being faithful in a reflection without repeating exactly what the client said. H14 described this experience:

"I think that the most challenging thing about using reflections is striking a balance between repeating back what they said using some of their exact words. So it just sounds like I'm fairly repeating versus I'm not wanting to infer too much into their situation and draw the conclusion that they didn't mean to say."

An improper usage of reflections could rather easily backfire, consequently making the helper appear robotic and not paying attention to the conversation. In the excerpt below from the conversation between $\mathrm{C} 4$ and $\mathrm{H} 4$, the client notices the helper is simply repeating them:

H4: "So 3C what brings you here ? :)"

C4: "Hi there, im having issues with getting my work done in quarantine" 
H4: "oh so you are having issues with getting work done in quarantine?"

C4: "yes thats what i said :("

In this case, $\mathrm{H} 4$ repeated the exact same words to the client which caused visible annoyance in $\mathrm{C} 4$, who responded with a sad emoji. In the conversation that followed, $\mathrm{H} 4$ commented they stopped using reflections altogether because it was not working for them as the client responded negatively to the reflective statements. In this case, it was clear that $\mathrm{H} 4$ was facing challenges in skillfully rephrasing the reflective statements.

Some participants went to the other extreme, adding too much additional information in their reflections in order to avoid sounding repetitive. For instance, H10 expressed that based on their experience, simply reflecting back what the client said was not constructive. Consequently, in using reflections to demonstrate their understanding, $\mathrm{H} 10$ added personal experience and interpretation to their reflections as demonstrated in the example below:

C10: "Yeah, for sure. My job, especially, has gotten more stressful in many ways due to quarantine. I just get really hard on myself for not being constantly productive."

H10: "Ah I see. Quarantining is tough. The first few days of it, I felt more free, but now I feel some sort of tiredness that hadn't been there before, and it's hard to explain. I feel it's especially difficult if you're someone who was constantly on the go and actively doing work/being productive before this all hit. This new situation just throws off that pattern/routine."

Even though reflection naturally involves rephrasing using the helper's own interpretation of the client's situation, providing too much interpretation and assumptions in a reflection could make the reflective statements quite inaccurate. In the case of the above example, H10 assumed that quarantine was throwing off C10's routine even though in C10's statement it only talked about the guilt of not being productive enough. In the case of H10, this pattern continued for the rest of the conversation. Even though the client was agreeing to the reflections throughout the conversation, it was mostly courtesy as the client in the feedback form submitted after the conversation wrote:

"They seemed to have kind of a simplistic world view, so I feel like they didn't understand the nuance of my situation. They were not super helpful. They described their situation in an effort to relate to me, and their situation seemed so easy it frustrated me."

4.1.3 Design implication. As participants reported, forming reflections is difficult: a proper rephrase that is different enough so it does not sound like a simple parroting of the reflected statement, but also at the same time keeping the statement faithful. Providing scaffolding for how to construct reflections that sound natural and faithful without being repetitive. In order to address this issue, we believe that platforms should provide resources for helpers to properly construct reflections in real-time by helping users choose proper words, phrases, and sentence structure, and opportunities for post-session self-reviews and evaluations on these statements. Proper words and phrases might be difficult to come up with on the spot and the structure of a reflective statement might be counterintuitive to how people are used to talking. However, these statements do follow a certain pattern and can even be identified using machine-learning algorithms [16]. This provides an opportunity for developing tools that can use such rules and structures to help novice supporters construct proper reflections. For instance, a possibility for design is using a machine-learning-based recommendation approach to help peer supporters construct a reflection statement, to nudge them in forming a statement by giving recommended phrases to use based on prior statements. For instance, peer supporters could highlight specific sentences in the conversation, and be provided with a list 
of suggested words and phrases that are similar to the language that the client used in order to construct a reflection. This real-time approach could help novice supporters on-the-go and help the supporters continue the conversation effectively. After the session, these reflections can also be highlighted in order for the users to review and learn for their future conversations.

4.1.4 Strategy: Learning the situation with questions. In order to understand the details related to the problems that the clients were facing, all helpers used some forms of questioning. Helpers reported using a series of questions related to the difficulty the client was facing to understand the background information and details that might be related to the problems. To the helpers, understanding all the details without going on a tangent required forming a working hypothesis of why the client was having trouble and then asking questions in that direction. If the hypothesis was wrong, or the information was incomplete, it was difficult to stay focused. However, this process was frequently the prerequisite for starting to piece the information together and directing the conversation towards change. $\mathrm{H} 1$ described this process:

"I was trying to, I rely on him to like go through what he has been doing recently and I do a fresh analyze. And it's a fresh analysis about your situation. I find out something new."

Below is a list of questions presented chronologically that $\mathrm{H} 5$ asked $\mathrm{C} 5$ at the early stage of the conversation in order to dig into the details and background of the difficulty that $\mathrm{C} 5$ was facing:

"Do you feel you have a lot more work than before?"

"Are you able to continue working in the same environment or are you also struggling?"

"Do you want to tell me a bit about your work habits and your commitments?"

"What are your main problems with working in your home?"

As this example demonstrates, H5's questions became more and more specific, going from simply whether $\mathrm{C} 5$ felt the workload was more to asking more specific details about the potential issue of working at home. The focus of the questions became more specific as $\mathrm{H} 5$ formed their hypothesis and slowly picked up the details of C5's struggles.

4.1.5 Challenge: Asking the right questions. This strategy of hypothesizing and trying to dig out the details and background information posed a challenge for the helpers as most reported that it was easy to jump too fast, or lose focus of the topic when they were trying to navigate through the client's experience to identify potential leads for further talk. H15 summarized this challenge:

"You have to make sure that those open ended questions are specific enough for the person to stay on topic instead of straying away from that topic. So like are the topic between this person and I about assignments, managing time and like daily routine? I asked those questions to make sure that we stayed on topic instead of just straying away to something irrelevant."

Continuing from the conversation example between $5 \mathrm{H}$ and $5 \mathrm{C}$ shown in the last section, $\mathrm{H} 5$ continued the conversation with additional questions. However, these exchanges took the conversation on a tangent:

H5: "Since you mentioned your advisor can I assume you're in a graduate program?"

C5: "Yup, a doctoral student in I/O psychology. What about yourself?"

H5: "I'm an undergrad in the Architecture program. You definitely sound very committed to your work. What are your main problems with working in your home?" 
C5: "Oh nice. I took an architecture class in my undergrad at Pitt that I really enjoyed. How far along are you in the program?"

H5: "I'm at the end of my third year, so two more to go Glad to hear! Was it studying architecture or creating models/drafting?"

As this example demonstrated, H5's intention appeared to be asking about more details of C5's current situation. However, the conversation ended up becoming an exchange of personal details. No doubt in a social situation, it would appear impolite to ignore such questions between H5 and C5's exchange. Consequently, the pair continued with even more exchanges on topics of architecture and even personal relationships. Similarly, H13 shed light on a comparable experience:

"I think as you noticed in the very beginning it was going off in a different direction and while I'm trying to be polite and helpful and not push him too much in one direction that, um, it seemed to go, you know, a little bit on a tangent and a few times throughout."

In the case of H13, the pair talked about music and politics until an experimenter had to intervene and divert the conversation back to procrastination due to the helper's reluctance to push the client and the need to be polite.

4.1.6 Design implication. As reported, asking the right question involves understanding the goal of the conversation and planning the questions around the topic of change. However, for inexperienced novices, it is challenging for both parties to ensure the questions do not divert. Therefore, designs to mitigate this challenge should focus on ensuring that both parties have agreed-upon conversation goals before commencing the conversation and these goals reminded throughout the conversation. Prior literature has suggested that goal-setting is an effective strategy to improve attention and engagement for learning activities [58]. Due to the complexity of the discussed content involved in a motivational-interviewing conversation, goal-setting could be a viable approach to ensure that the parties focus on the important topics, improving attention and engagement and ensuring that the topic of change stays the center of the conversation. For instance, a specific design strategy could be pre-session exercises that detail the expectations and goals of both parties. Before the conversation starts, the client could be asked to write a brief summary of what they would like to discuss. The helper in return could read the summary and come up with a set of goals that they aim to achieve before the end of the session. During the session, the goals could be displayed on the side as a road map for the conversation. For every goal accomplished, the helper could choose to mark them as finished. Having the goals always on display and making sure that they are checked off could potentially aid helpers to remember what needs to be accomplished and avoid going on tangents. These approaches help visually remind the interlocutors of the conversation focus and the progress that they are making.

4.1.7 Challenge: Managing cognitive load. Some helpers also mentioned difficulty managing the cognitive load when the response to their questions become overwhelming, especially on a textbased platform: some clients typed very fast and produced long paragraphs that needed to be broken down. It became difficult to follow the client's pace, as well as to find the important information in the long messages and respond to them. H15 said:

"The partner started out with a very big passage at the beginning where I had to like read it out loud to myself to make sure that I was comprehending what they were saying and just to make sure I could read between the line, and if there was anything that I was missing. So yeah. If you just look at that huge chunk of texts, I was like, Oh, okay. Um, like I had to break it down and I read it out loud to myself." 
At the same time, on top of the difficulty of following the pace, helpers were also all very careful about making sure to capture and respond to everything the client said to make them feel heard. This sometimes posed rapport building challenges. H5 explained:

"I think because people are used to sort of like a natural flow of conversation and you don't want people to feel ignored. You do sort of want to respond to it all, but then your response is sort of gets jumbled up with the question. Especially since everything in a text is sort of like in a linear format from top to bottom. You don't have like the back and forth."

This challenge has been documented in prior search on instant messaging platforms. Text-based conversations are fundamentally different from oral conversations as there are no speakers and hearers but have instead writers and readers [66]. In oral conversations, the formation of the speech and the hearing and interpretation process occur simultaneously. This process in text conversations does not happen in real-time and require instead the interpretation process for reading and writing instead of oral communications, therefore taking much more time and effort especially when a large amount of information is being exchanged between the parties [27].

4.1.8 Design implication. As reported by our participants, conversing through a text-based platform brings about its own set of difficulties. Text-based conversation do not happen "in real time" so to speak. Responses are composed and often scrutinized before being sent, and a large amount of content could consequently be thrown into the conversation at once with a long response. This also means a delay in not only composing the message, but also for the receiver, the time needed to properly interpret the response [27, 66]. We believe the best way to mitigate this delay of response as well as cognitive load is introducing lightweight strategies that could help control the pace of the conversation and reducing the silence and information processing times between exchanges. One potential strategy is introducing a chat interface that allows both parties to see the conversation happening in real-time, seeing messages being composed by character, similar to [36]. This approach reduces the duration of silence between messages as the conversation is being read as they are happening, and helps speakers to convey non-verbal cues [36]. At the same time, it prevents information-laden messages being sent as heavy text blocks, allowing helpers the time to properly read and understand the messages as they are being composed. This approach also allows the conversation to take on a more similar format of traditional talk therapies as well as support groups.

\subsection{Subgoal: Rapport building}

4.2.1 Strategy: small talk. The most common strategy that helpers used to build rapport with clients was small talk, that is. Helpers often started to talk about unrelated topics such as weather, music, politics before properly ease themselves into a support conversation. 12 out of 15 participants engaged in some form of small talk throughout the conversation. This typically happened at the beginning of conversations. Below is an example of how H5 used small talk to start their conversation with $\mathrm{C} 5$ :

H5: "Hi! How are you today?"

C5: "Hi i’m good, how are you?"

H5: "I'm also doing good. I'm enjoying the great weather today. What has you feeling good today?"

C5: "Nice. My weather here is not so great. Um, just in general that besides workload, other aspects of my life are going well"

H5: "Aww that sucks to hear. I completely feel you on that part with the workload.

Do you feel you have a lot more work than before?" 
4.2.2 Challenge: awkward initial interaction. The excerpt above was a good example of how helpers typically started conversations with small talk such as questions about the weather. However, most participants felt this type of interaction was awkward. H5 commented on the excerpt above:

"Typically I don't feel awkward meeting people. It was just like after reading the guidelines, I was very aware of the person and just trying to be like a good listener and ask like open ended questions, which feels a little forced in the beginning."

Similar to H5, 10 other helpers also reported feelings of awkwardness during initial interactions with the client.

Helpers felt having to build rapport for the purpose of conducting a support conversation was awkward and forced, particularly in a situation where neither participant really knew the other or the standard accepted norms of behavior. H5 described how the pre-session training made them acutely aware of their helper role in the conversation and that trying to frame their behavior around the guidelines which resulted in awkward initial interactions. H15 shared a similar concern with building rapport in a manner that violated the guidance they received:

"I think it was just at the beginning where I was a little, I guess, awkward and yeah, I was kinda worried that like maybe I was just doing something wrong. Yeah, I was worried that I was kind of going against the instructions, but I don't think I necessarily was cause I was just getting used to it."

In this case, heightened attention to building rapport made the experience less natural. At the same time, the problem was exacerbated by the fact that typically this kind of intimate conversation about self-disclosure was something that usually happens between close acquaintances. Talking about a problem with a stranger was a foreign idea to most participants. Therefore, it made building rapport also difficult. H13 talked about struggling because of lack of familiarity with the other person and the medium:

"Of course not knowing anything about the other person makes it a little harder for me... Um, this is stuff I've only ever done face to face with someone that I know a little something about them." - H13

4.2.3 Challenge: The therapist-friend role confusion. The second challenge that helpers faced was confusion about what "role" they were supposed to play and how to play it properly, reported by 9 out of 15 participants. Helpers believed that the role they were given had inherent expectations: offering expertise and helping someone in need. However, based on the demographic data collected, helpers did not have any qualification or expertise to behave as peer supporters beyond the training they received as part of the experiment. The helpers in our study frequently reported experiencing an "identity crisis": they were not certain whether they should be "pretending" to be neutral and formal like a professional therapist with the authority that the study gave them, or trying to be warm, open and friendly, sharing their own experiences like a friend. For instance, H6 said:

"...as a participant, you know, I would probably try to find some mix between the conventional talking a friend through their troubles and what a psychologist's expected to do in the sense that I try to maybe, maybe put a little bit extra emphasis on listening and viewing them as capable versus being, uh, you know, really, really getting into that ego trip of being the authority figure or being the person that the person is coming to for advice."

In this case, $\mathrm{H} 6$ expressed a desire for a "middle ground" between being a therapist and a friend. In professional counseling and therapy situations, it is discouraged for therapists to develop personal relationships with clients or share personal experiences, chatting to the client like a friend. Amateur peer-support conversation, however, do not have clear guidelines to their behaviors with the client. 
4.2.4 Design implication. These two problems addressed above share certain similarities: they both stem from a lack of experience interacting with clients in such a novel environment and context: uncertainty on how to behave in a new role. This problem that novice supporters face is not so different from novice therapists face with transitioning into professional counselors and therapists. Novice therapists frequently struggle with adopting the role of a professional helper, transitioning from a different career that they might hold previously, or from being an informal helper for friends and family to a professional therapists [14]. Clinical supervision as well as continued contact with the clients [14] are common strategies to manage this challenge. However, in peer support interactions clients as well as the helpers do not necessarily always expect a professional relationship. From our observation, a large number of conversations take on a friendly tone. At the same time, the role of a peer-supporter is clearly not the same as a professional therapist and they provide different types of support. Moreover, canonical guidance and training on how a peer-supporter should behave around clients is not clearly defined. Evident from our results, there exists a lack of clear guidance on what to do and how to behave for such a novel experience. To address these issues, we believe that platforms should provide resources and opportunities for community-based knowledge sharing and guidance on how to properly behave as peer-supporters. A large support platform, where tens of thousands of supporters gather, can foster a plethora of user- and community-generated resources. The valuable part about such platforms is that there are experienced helpers who share a common goal of helping others. As we discussed, clinical supervision is a common strategy for novice therapists, a potential design solution could be community-based shadowing and mentorship that allows senior members of the communities sit in conversations and provide real-time pointers and feedback as well as post-session mentoring and reviews on the novice supporter's performance. Another potential design is practice interacting with clients and clarifying their roles through role-playing with more experienced supporters. Prior research has shown that role-playing is as effective a method for skill-development as real conversations with clients [44]. Novice supporters could practice conversations with more experienced members in order to refine their skills and receive guidance on how to behave in their new role around clients.

4.2.5 Strategy: Show empathy. Aside from small talk, helpers also reported developing rapport with the client by showing that they understand the participant's feelings in order to ensure a smooth conversation and good relationship between the two participants. On this topic, H9 said:

"...if a helper relates to the person having the problems, the conversation flows better. And getting to know the person definitely is easier because it's someone who you can relate with and someone who understands you."

For instance, in the conversation excerpt below, $\mathrm{H} 1$ was empathizing with $\mathrm{C} 1$ in order to show that they understood C1's feelings. H1 validated C1 on their feeling on procrastination during the pandemic. H1 further explained in the interview that they wanted to make sure that they understood C1's concern and C1 could feel heard and understood in the situation in order to build rapport.

H1: "How are you doing, what brings you here today?"

C1: "thanks for asking! tbh, i'm not doing so great. i've been dealing with this procrastination issue at work lately especially during this pandemic time, when we're sort of forced to stay at home and work from home."

$\mathrm{H} 1$ : "Oh sorry to hear that! I totally understand it's not easy for anyone in this situation" 
4.2.6 Challenge: Conveying non-verbal cues. Difficulty in conveying and interpreting non-verbal cues is another common challenge that were noted by participants. Non-verbal cues are an important part of how people express themselves and their feelings in real life. However, being in an online environment makes this task much more difficult.

All helpers mentioned difficulties conveying non-verbal cues indicative of their empathy and emotions over text. As [23] pointed out, virtual sessions do not provide the same affordances such as being able to convey non-verbal cues. In our case, helpers reported it was difficult not only show the other person that they are empathizing and actually paying attention, but also to interpret what the other person is feeling and saying. H3 said:

"Cause there's also no, there's ways, there's no tone of voice. If you're speaking a sentence and you wanted to go on, there are so many flexible ways of changing your speech. You know, you can leave it on a high note or take a breath and continue. There's so many ways of pacing that whereas with the texting, you know, if you just see that someone is typing, you wonder, well has this finished? Where should I interject what's, what is the etiquette and the sort of way of sending signals around this texting."

Helpers looked for other ways to express emotion and tone via text. Helpers reported using emojis and exclamation marks in order to convey a certain tone of voice. However, relating to the therapistfriend struggle, some helpers expressed concern over whether using emojis was appropriate and professional for this situation. Nonetheless, most participants expressed a desire for more ways to convey emotions such as searchable emojis and GIF stickers.

4.2.7 Design implication. Consistent with our findings, prior research has outlined challenges with conveying tone in text-based communication [17]. It has also been well established the difference in affordances of text-based communications versus verbal communications. [80] pointed out that there are certain levels of non-verbal cues that can be transposed and expressed through text and facilitate rapport-building. Additionally, tokens such as punctuation marks and emojis are commonly used as alternatives to non-verbal cues, which help convey emotions but also are prone to misinterpretation [31, 78]. However, [80] also suggested that in situations where interlocutors do not expect to establish a long-term relationship, the lack of vocalic, kinesic, proxemic, and appearance cues found in verbal communication is predisposed to engender deindividuation of the speakers, resulting in the reliance on stereotypes based on the first available characteristic that one learns about the other speaker. The deindividuation effect would be even more detrimental in a situation where one person expects emotional support for difficult topics. In our context, users who engage in online peer-support conversations frequently expect anonymity and do not necessarily seek to build long-lasting relationships. Therefore, it is especially important in this context to facilitate the expression of non-verbal cues. To address this issue, one of the prior design suggestion of a messaging system that allows visible composition by character that we mentioned in section 4.1.8. Additionally, other channels of alternatives to non-verbal cues should be considered. One example of such design is emojis and reacts that is found commonly in messaging platforms. Alternatively, virtual avatars and embodied agents could also be another way of expression. [30] found that emotions and non-verbal cues conveyed through virtual avatars and embodied agents affect participants' social evaluations. Incorporating avatars or virtual agents that could help both parties express real-time emotions through in-the-moment virtual facial expressions by proxy of the avatars could potentially strengthen the communication and expression of non-verbal cues between the speakers. Moreover, camera-enabled tracking that automatically transposes speaker's facial expression virtually could further enhance this feature. 


\section{PROMOTING READINESS FOR CHANGE}

After building an understanding of the client and their needs, the second goal we gave the helpers was to promote readiness for change through the conversation. What this means is for the helper to prepare the client with a mindset that is more open to changing: for instance, from having no plans to having plans, from having plans to committing to the plans. This corresponds with the overall idea of motivational interviewing: to encourage clients to talk about making changes and ultimately committing to it. We identified two components that helpers worked to achieve for this conversation goal: provoke commitment, and instill client self-efficacy. In other words, this meant for the helpers to encourage the client to voice their wish and plans for changing, and then help them feel confident about their ability to achieve the change.

\subsection{Subgoal: Provoke commitment}

5.1.1 Strategy: Leading the conversation. Most helpers tried to push the conversation towards change with somewhat leading questions and statements. It was a common practice in our sample for the helpers to attempt to achieve this goal by "nudging" the client and asking questions that led towards the topic of change. H9 explained this process:

"... asking another person questions so that they can think through the process themselves and they can find the answers themselves, almost like guided questions almost. So it was like helping drive their thinking process... Having them answer their problems through themselves definitely helps them feel more accomplished. And it's a really good strategy because it's just, we helped with that first and then they feel more empowered."

This conversation excerpt from $\mathrm{H} 9$ and $\mathrm{C} 9$ demonstrated how $\mathrm{H} 9$ used leading questions to push C9 towards recognizing the benefit of starting projects earlier and committing to change.

H9: "Do you feel like the hardest part is starting the project?"

C9: "yes. there's a lil bit of a barrier in my mind. "

H9: "Maybe the second biggest reward could be for starting it!"

C9: "i hate the thought of having to do the work"

H9: "Same! But once you start, how does it feel?"

C9: "but then it gets better once i start the actual work. it's like you can do a better job once you know where your project is going"

H9: "And you usually get over the barrier because of a deadline right?"

C9: "hahah yes"

H9: "You definitely enjoyed the feeling after getting over that barrier too right"

C9: "sometimes its really late at night sometimes it's the day of. but i do kind of get relieved once i kick into a groove while im workin. it's kind of like finding your pace when you run."

H9: "perfect! that groove feels so great. so do you think you can get that groove in earlier?"

C9: "That's the thing, the more i procrastinate and have the horrible panicky feeling, the more i try to avoid it. so finally after doing this for a while, im realizing if i sit down and start it earlier, then it's easier to continue later. it's easier to have a plan or an outline for the work before i try to jam it out the night before it's due."

H9: "and that's why the mini deadlines help. from your teachers especially" C9: "yes! definitely" 
As we could see from the excerpt, C9 started with reluctance to change as they said there was a "barrier" in their mind for starting the project. H9 focused on the positive feelings of starting the project and guided the conversation through leading questions such as "you definitely enjoyed the feeling after getting over that barrier too right?". This completely changed the conversation from talking about the difficulty of such a task to focusing on the positive feelings associated with starting the project, and ultimately made $\mathrm{C} 9$ excited about their plan and actually committing to change by the end of the conversation.

5.1.2 Challenge: focusing on the client. Best practices in motivational interviewing encourage the client to take on the role of talking [59]. However, frequently, while leading the conversation, helpers fell into the trap of sharing a personal experience as a example or motivation for the client, which frequently resulting in diversion of the focus. Nine out of fifteen helpers employed this approach even though in our training participants were explicitly discouraged from sharing too much of their own experience. We observed that the participants who employed this approach all took the focus of the conversation away from the client when sharing their experience, often sharing elaborate details and receiving multiple follow questions from the client. For instance, H7 said:

"My partner had mentioned his age or they mentioned their age and I mentioned that I was older and I think that led to kind of a little bit of an exchange of personal information. And I had mentioned that I had worked full time but also had periods of time where I, where I did was doing a gig work basically. And he asked, can you actually make enough to live off? And to me it felt helpful to provide him with an, the answer to that, an honest answer to that. So I gave that personal information, which I wasn't sure... that might've been a little too much. I kind of wish he hadn't asked that even though I opened the door and then I tried to... turn the conversation back to back to that, the individual's experience instead of my experience."

Even though in this case $\mathrm{H} 7$ did realize that they might be sharing too much and took away the conversation focus, more frequently than not, helpers who employed this approach did not realize this issue. Below is the expert from the exchange between $\mathrm{H} 7$ and $\mathrm{C} 7$ that $\mathrm{H} 7$ commented on above:

C7: "That sounds really interesting, can you actually make enough to live off of?"

H7: "Well, in those instances I had some amount of savings or credit line I could tap, and also was getting unemployment. Have you ever looked for various opportunities on Craigslist?"

In this case, $\mathrm{H} 7$ successfully shifted the focus back to the client by asking a question. However, they spent a significant amount of time discussing details of H7's experience instead of how C7 was planning to deal with the issue. This type of incidents are not uncommon. Sometimes one simple misplaced statement could move the focus entirely away from the client, whether the helper realized or not. However, it was also difficult to maintain this focus on the client because they might be reluctant to finding the solution from their own experience and instead push very hard for the helper to give advice or suggestions. For instance, H2 commented:

"I felt that by deflecting his questions and his consistent push for advice I was just kind of ignoring him and ultimately I was like, Oh, ignoring him isn't really quite like empathetic, it just seemed that what I was doing was really cold on my end, even though I was trying to give him affirmations and saying, okay, let's try and figure this out together." 
Therapist self-disclosure is a common issue found in therapeutic conversations. Prior literature has suggested that there are commonly ethical as well as practical concerns surrounding therapist's self-disclosure. For instance, in situations where the client and therapist have yet to establish good working relationships, therapist self-disclosure could lead to clients rating the conversations shallow and questioning the therapist's expertise; however, positive outcomes often requires expertise and nuance in the therapist's clinical skills $[6,46,53]$. In our case, certainly the role of a peer-supporter is different from a therapist: they do not provide official or medically valid treatment or help to the client. However, this issue is still interesting in our context because self-disclosure in online anonymous conversations that provide peer-support still can lead to potential privacy concerns. Moreover, establishing working relationships for amateur peer-supporters should be much more difficult than a professionally trained therapist. Therefore, it could also have detrimental impact on the client's perception of a session's usefulness and the helpfulness of the supporter.

5.1.3 Challenge: Avoid giving advice. Prior literature on MI and other therapies suggest that clients judge collaborative conversations where the therapist does not dominate and tell the client what to do more as more helpful $[1,45]$. In our training, we explicitly discouraged helpers from providing advice to the client, consistent with motivational interviewing spirit of letting client solve their own problem. However, 11 out of 15 participants gave their client some advice, and 8 out of 15 helpers reported it difficulties in refraining from giving advice, especially when they wanted to point the client towards changing their behavior. H14 said:

"I think that the most challenging thing was coming up with a solution with the other person, but refraining from trying to give them advice or being very forward in my suggestions. Instead I tried to promote a collaborative relationship and kind of get them to take the lead on solutions because, um, they know their situation best."

This quote also pointed out why helpers should not give advice: an advice might be completely inapplicable because the client's situation could be very different, or it might have been something they already tried, which could result in the client's distrust, demonstrated by the following example:

H10: "Another thing you could do is talk to those who are close to you about these goals you've set and they can also be a motivator for you, reminding you of important items you need to get done"

C10: "Yes, I do do that too sometimes. It's tough with work though because it's a lot of privileged communication."

In this case, C10 pointed he had previously tried H10's solution but that it was not applicable because of the nature of his work. In the rest of the conversation, H10 dominated the conversation providing personal experiences and giving a lot of advice. This pattern led C10 to be dissatisfied with the conversation.

5.1.4 Design implication. We believe that there are two important similarities between the challenges of focusing on the client and refraining from giving advice. First of all, helpers sometimes do not have the self-awareness of their own behavior, such as becoming dominant in the conversation or providing too much advice, because they are so used to doing so in daily conversations. Helpers rarely realized when they were taking over the conversation or providing too much advice, as $\mathrm{H} 7$ pointed out above. Tools to give helpers real-time feedback to identify and highlight potential MI-inconsistent behaviors could help solve this problem. Detecting and providing feedback on conversation metrics or features like relative speaking time or average turn length could help ensure the focus being on the client. Prior work such as [37] demonstrates how providing feedback about dominance of conversations can help balance conversations. In our case, text-based metrics 
such as total word count are possible: if the helper produces content over some threshold (e.g., $50 \%$ of the total words), the platform could alert the helper that should giving the client more opportunity to talk.

To make sure that helpers refrain from giving advice, a machine-learning based approach could potentially be used to solve this problem. Machine-learning has been frequently employed in analyzing therapeutic and support conversations. For example, Wang et al [81] built classifiers to identify advice giving in online support conversations. With this approach, a tool could parse composed text messages before they were sent and warn helpers if they offered advice.

The next layer of the problem is actually behaving in a MI-consistent way and try to correct the problem. Evident from our result, it is uncommon for helpers to be able to identify an alternative statement that they could use that follows the spirit of MI that encourages client self-discovery. To help the supporters to provide more MI-consistent responses, we suggest providing helpers with examples and commonly used responses in real time. One potential implementation is that once it is identified that the helper is not focusing on the client or is giving advice, the algorithm provides a list of community- and user-generated responses that are good ways to redirect the conversation, or alternative responses to suggestions such as "I'd love to share my experience more but I want to make sure the focus is on you." and "what do you think you can do?".

5.1.5 Challenge: Helper's self-efficacy. Even though helpers attempted to lead the conversation towards change, they also reported uncertainty to whether they were being helpful in the conversation due to the lack of expertise in certain topics. Even though the topic of our study was procrastination and participants were asked to hold a conversation related to the topic, there were different ares in which people procrastinated. For instance, $\mathrm{C} 10$ talked about details of procrastinating on a case as a lawyer, $\mathrm{C} 2$ mentioned procrastinating on taxes. Therefore, helpers were not necessarily familiar with a certain situation that a participant brought up, which lead to the helpers doubting their helpfulness. In the case of $\mathrm{C} 2, \mathrm{C} 2$ asked $\mathrm{H} 2$ for help on making plans to do taxes. $\mathrm{H} 2$ reported that being in the helping role was difficult because they did not have any expertise in taxes specifically. In this case, even though the helper responded with "Can you think of any other resources to look at?" and quickly shifted the question back to client, $\mathrm{H} 2$ reported feeling uncertain about themselves. They commented:

"...and so when they're talking about like, tax, I'm just like, well, okay, like, I don't really know if first of all, I'm capable of even like helping them through it and also just like, I don't want to give them like wrong advice or maybe like give them the wrong idea of like, what they're doing, you know, is correct."

Similarly, H10 expressed a similar sentiment:

"...if I were an attorney and I had the background of an attorney and I knew what would happen if I didn't do my work on time, or did it too slow or whatever... if I had that background knowledge, I maybe could have given more relatable advice."

In the case of both participants, they pointed out the lack of knowledge in the specific area in which the client had problem with reduced their perception of their potential helpfulness to the client. This therefore had significant impact on the helper's self-efficacy: helpers were not certain if what they were doing was actually helping the client change. At the same time, there was not a way for them to know whether their responses were helpful to the client. Therefore, helpers often felt encouraged and helpful when the client overtly stated that the conversation has been helpful. However, in this case the result is interesting. The helpers' self-diagnosis of their lack of skills focused on the specificity of the problems: doing taxes, or being an attorney. However, MI 
teaches conversation skills that aims at self-discovery and should be applicable across domains [59]. It is evident that this insufficient understanding of the MI skills and the spirit of MI, which is not to solve the client's issue but help them with self-discovery, influences the helper's perception of their capability.

5.1.6 Design implication. A commonly reported and discussed topic, therapist self-efficacy remains an important factor for skill development. Prior research has proposed mainly clinical practicum and supervision as one of the more common and effective interventions aimed at improving therapist self-efficacy [35, 70, 82]. These research provides strong support in our case for a communitydriven approach that aims to provide models for the novice supporters to learn from, previously outlined in section 4.2.4. As Bandura outlined in his work, self-efficacy mainly comes from four dimensions: performance outcomes, referring to seeing the positive or negative outcomes of one's action; vicarious experience, referring to learning from modeling someone else; verbal persuasion, encouragement or discouragement of one's ability to perform; and physiological feedback, how people perceive physiological and emotional arousal related to their performance [7]. We mentioned previously designs that allow novice helpers to sit in conversations conducted by experienced helpers. This aligns with Bandura's idea of vicarious learning and can help to also allow novice helpers to see the MI skills' effectiveness, and understand that the spirit of MI is not having the expertise on every topic, but having the expertise to be able to help the client with self-discovery. On a different level, allowing and encouraging more experienced helpers to coach novices in real-time, providing affirmations and encouragements when skills are properly used can also help on the dimension of verbal persuasion to help novice develop the confidence in their own skill usage These approaches can not only help novice supporters in developing their self-efficacy, but also helping them better understand the goals and spirit of MI. Lastly, we also noticed the possibility of helper's personal information being a factor in influencing their self-efficacy: for instance, H10 knowing they were an attorney and H10 being unfamiliar with the profession. Even though the spirit of MI is domain-independent and change is reliant on the client's self-discover and insight, minimizing the personal information sharing in these conversations could potentially minimize the psychological barrier caused by the perceived need of expertise or status difference.

\subsection{Subgoal: Instill client self-efficacy}

5.2.1 Strategy: Empower with affirmation. The last strategy employed by helpers was to affirm the change-related behaviors or statements in order for the clients to feel empowered and able to change. Affirmation means using positive statements in response to highlight a fact or behavior from the client. Helpers believed that validating and encouraging client was effective in helping the client feel good about themselves and stay motivated for making the change. For instance, H9 said:

"I made sure to say that I'm proud of them and to affirm them for that because definitely affirmation helps in stuff like this or, and it depends, but usually it helps. It helps them feel better about themselves because it's a problem they have but I let them know that they have the skills to solve it"

Continuing on the example between $\mathrm{H} 9$ and $\mathrm{C} 9$ from previous sections, below is an excerpt towards the end of the conversation where $\mathrm{C} 9$ was expressing doubt again about their ability to accomplish the change.

C9: "yeah, and then ill tell my roommates so they can help me remember too"

H9: "and then your roommates could get on the system too"

C9: "i really am bad a keeping my own deadlines"

H9: "and then your whole place would smell like brownies"

C9: "yeah so they'll help a lot because they're much better" 


\section{H9: "hey that's okay though that's what roommates are for! and you're good at keeping the small deadlines for teachers. your system can help you do your own deadlines now"}

H9 responded to C9's statement of self-doubt with an affirmation from a different angle and reminded them with the things that they were able to do and that they were not alone in the situation. The conversation ended on a positive note for both participants.

5.2.2 Challenge: Being sincere. The most common difficulty that participants faced with this strategy was being sincere with their affirming statements. Even though all participants reported using the skill and finding it helpful, however, four participants believed that simply affirming everything appeared insincere and it was difficult to strike the balance of affirming the right statement. H7 said:

"I guess in a natural conversation you might have different criteria for when to offer praise. But in this conversation as we were instructed to do it, I felt like I was providing praise, not that it wasn't justified to some extent because the things that I was saying, 'Oh, you're good at this or that you're really skillful'. In those instances, I didn't think I was lying, but I thought that maybe I wouldn't have mentioned it as often. And so I felt a little bit, uh, a little bit just a touch uncomfortable with it because I feel like I'm using it to make them feel good ... and to keep them engaged in the conversation instead of to really praise that person."

In this quote, it was clear that $\mathrm{H} 7 \mathrm{did}$ not feel comfortable using the skills with ulterior motives, in this case maintaining the client's engagement. Even though that they were not lying with the affirmations, the fact that the behavior was being used to achieve a explicit goal and thus, in a sense, to manipulate the client, rather than being a natural reaction during conversation, made the helper uncomfortable with sincerity.

5.2.3 Design implication. The helpers expressed that using MI skills made them sound insincere because of the difference from normal daily conversations. In order to address this, we believe it is essential for the helper to realize that using MI skills and maintaining sincerity are not contradictory. We recommend a design approach that encourages self-practice of the skills. [13] and [73] pointed out the importance of "buy-in", referring to therapist actually experiencing the skills that they are using on the clients, and self-practice. They suggested that experiencing the skills as the therapist is important for not only understanding the client's perspective but also the therapist's own skill development. Similar to [13], we suggest lightweight self-practice exercises that focuses on specific skills at a time. For instance, the client can be asked to compose affirming statements for themselves, and reflect on their own feelings of being on the receiving end of these skills. Another possible design is encouraging helpers to be clients and go through a session talking about a real issue they might be experiencing with an experienced helper before they start as helpers.

5.2.4 Challenge: Affirming the right element. Even though affirmation was a common strategy for helpers to promote change, at the same time, affirming the wrong element could have more consequences than simply appearing insincere. Encouraging change with affirmations could bring a sense of empowerment to the client. However, affirming a statement in which the client expresses the wish to maintain their current behavior could also encourage them to feel good about their current behavior, that their current situation is good enough, and consequently lowering their readiness for change [59]. For instance, in this excerpt between $\mathrm{H} 8$ and C8, C8 produced a statement that showed they wanted to maintain their behavior which was affirmed by $\mathrm{H} 8$ : 
C8: "But I think another factor is how I study because if I study in advance but only a little each day with a lot of distractions compared to study the night or two nights before, it sometimes has the same effect on my performance if that makes sense. So I think time management is something that is unique to everyone based on how they retain information or how they keep up with a task."

H8: "Yeah that makes sense. It's definitely good to do what you think is best for you!"

C8 in this case is claiming changing the procrastination habits or not would produce the same effect, similar to common examples in motivational interviewing of substance abuse clients claiming other users they know are not disease-ridden or they would function worse without the substance [59].

5.2.5 Design implication. Identifying sustain talk is one of the more challenging aspects of motivational interviewing [59]. The acquisition of difficult skills such as this could only come from continued learning and practice. One example is continued training using post-session self-reflections. [63] demonstrated that making MI students analyze their own conversation after session was an effective way of training and skill development. In the case of identifying sustain talk, it is rather a specialized skill that might be difficult for novice helpers to notice on-the-spot. Post-session self-reflections can not only allow the helpers to have time to think and ponder on the nuances of client statements, but also identifying potential mistakes that they might have made during the conversation. Moreover, a more community-based approach could consider allowing supporters to mark any sections in a support conversation where they are confused about whether the skill usage is correct or appropriate, and send it in for feedback. Other more experienced supporters who have gone through a certain platform-specific "expert certificate" process could provide a community-rating of the excerpt as a form of maintaining their "expert certificate" as well as some other potential rewards [56]. This approach can be used for not only this challenge, but also as an integral part of skill development that can help to address other skill-related challenges. However, certainly this might not be the only challenging aspect of MI. We believe the design implication for this should be more generalized to acquiring difficult skills in MI. We further discuss the implication of a systematic way of scaffolding a better experience to support novice helper's skill development below.

\section{DISCUSSION}

This study examined the experiences of a peer-support conversation from novice supporters' perspective. Through the lens of motivational interviewing, we also provided a theoretical structure to understand what helpers go through, what strategies they use, the challenges they faced, and how one can improve this process. In summary, helpers utilized a variety of strategies to understand the client's situation and promote readiness for change, with challenges associated with each strategy. To achieve their first goal of understanding the client's problem, helpers used reflections and questions to probe for details and test hypotheses but had difficulty getting the reflections right, asking the right questions, and properly processing the responses. Building understanding also required helpers to build rapport with clients. They typically achieved this through small talk, albeit laden with some awkwardness, and by displaying empathy. But showing empathy was made harder by the text-based platform. For the second conversation goal of promoting readiness for change, helpers tried to lead the client by using leading questions and statement. However, they too frequently shifted focus away from the client, gave advice when they shouldn't have, and were not confident in their ability to provide help. Lastly, after getting verbal commitment from the clients, helpers also tried to make the clients feel they could change by empowering them 


\begin{tabular}{|c|c|c|c|c|}
\hline \multirow{2}{*}{ List of design implications } & \multirow{2}{*}{ Challenges addressed } & \multicolumn{3}{|c|}{ Intervention window } \\
\hline & & Pre-session & In-session & Post-session \\
\hline $\begin{array}{l}\text { ML-based real-time text analysis } \\
\text { and feedback }\end{array}$ & $\begin{array}{l}\text { Faithful reflection } \\
\text { Focusing on the client } \\
\text { Avoid giving advice }\end{array}$ & & & \\
\hline $\begin{array}{l}\text { Goal-setting and in-session } \\
\text { goal-tracking }\end{array}$ & Asking the right questions & & & \\
\hline $\begin{array}{l}\text { Seeing messages composed by } \\
\text { character }\end{array}$ & $\begin{array}{l}\text { Managing cognitive load } \\
\text { Conveying non-verbal cues }\end{array}$ & & & \\
\hline $\begin{array}{l}\text { Community-based knowledge } \\
\text { sharing }\end{array}$ & $\begin{array}{l}\text { Awkward initial interaction } \\
\text { Role confusion }\end{array}$ & & & \\
\hline $\begin{array}{l}\text { Self- and community-based } \\
\text { reflection and feedback }\end{array}$ & Affirming the right element & & & \\
\hline $\begin{array}{l}\text { In-session mentoring and } \\
\text { shadowing }\end{array}$ & $\begin{array}{l}\text { Awkward initial interaction } \\
\text { Role confusion } \\
\text { Helper's self-efficacy }\end{array}$ & & & \\
\hline $\begin{array}{l}\text { Virtual avatars, emojis, and } \\
\text { reacts }\end{array}$ & Conveying non-verbal cues & & & \\
\hline $\begin{array}{l}\text { Experience skills first-hand } \\
\text { through self-practice or being } \\
\text { the client }\end{array}$ & Being sincere & & & \\
\hline
\end{tabular}

Fig. 2. Design implication aligned with their respective intervention window

with affirmations. However, helpers felt their affirmations weren't sincere and had difficulty only affirming the change-positive qualities in the clients.

\subsection{Towards a systematic approach for supporting novice peer-helpers}

Our results and designs imply a broader and more systematic way to support novice helpers. We have identified a number of distinct challenges novice helpers face and suggested possible solutions for each. But rather than treating each problem piecemeal, we believe it is important to identify commonalities between them and their solutions. More specifically, we see three main windows of opportunity to support helpers, and interventions during each window have the potential to make it easier for helpers to overcome multiple challenges. The windows of opportunity for interventions are before a support session starts, during the session itself, and after it is over. In figure 2 we aligned and summarized the previously mentioned design implications under these three windows for intervention. In the following sections, we explain these three windows more in detail and how together they construct a unified system of support.

\subsection{Pre-session: helping with preparations}

Our design implications suggested interventions such as goal-setting and other activities that happen before a session starts. We believe that the time before a session starts is one crucial moment in building a systematic support infrastructure. The goal of this stage should be providing relevant information that allow helpers to anticipate what is to come and can be accessed during the session if necessary. Due to the complexity of MI skills, especially for novice helpers, preparation should be considered an essential first step in improving helper skills and session quality. The pre-session stage has traditionally been used for a variety of preparation activities in clinical 
settings, such as reviewing session notes and planning agendas for the session [11]. These presession interventions in traditional therapy should be considered as inspiration for designing for amateurs. Because amateur supporters often have minimal training and experience, preparation activities could be especially helpful by providing information that amateur helpers lack or are unable to come up with quickly in a session so that this information can be on hand during a session. Throughout the interview, helpers frequently mentioned the helpfulness of some examples that we gave from the training material, and how they were able to have immediate access to the examples and modify them accordingly to use in their own conversations when they get stuck. This demonstrates the need of proper support during the preparation stage and providing helpers with resources that can anticipate what might happen in the session. For instance, as we mentioned in the results section, challenges associated with managing the session flow, such as asking the right questions avoiding awkward initial interactions could be properly addressed with adequate presession preparation: reviewing the client's information, setting goals, getting reminders about keys skills, and preparing questions. Designers should consider activities that guide novice supporters through this preparation process and use a variety of exercises to better understand the background of the client, the goal of the session, and have a plan for what they should do during the session.

\subsection{In-session: machine-learning-based real-time support}

The next opportunity for scaffolding is during a session itself, providing immediate feedback and reminders for the helpers about mistakes or opportunities to improve the conversation. As reflected in figure 2, a variety of problems could be addressed with appropriate in-session real-time feedback and activities, whether it is human- or machine-learning-based. These challenges that we discussed and designs we proposed revolve around the helper being able to identify difficulties and provide alternative responses in real-time: for instance, identifying when the focus of the conversation has shifted away from the client or the helper is offering advice. As helpers often do not have the capability to properly analyze their own behavior in the moment and recognize problems that come up, real-time feedback during a session could improve helpers' self-awareness. Research has rarely looked at the potential of providing real-time support for therapists during traditional therapy sessions. This difficulty could have been partly due to the delivery method: face-to-face, spoken conversations require more difficult natural language processing and faster responses than text-based conversations. We believe, however, a text-based platform makes real-time analysis and support easier. In traditional therapy the identification of the mistakes committed commonly happens with after-the-fact clinical supervision and coaching [14]. Emerging machine learning tools can reduce the need for manual supervision, where consistent linguistic patterns and metrics can be used to identify problems. However, the limitation of current technology in natural language processing limits the complexity of content that can be identified. For example, [71] used machine learning to automatically code MI conversations and found that their algorithm was more effective than human coders in identifying "formulaic" content like open versus closed-ended questions and affirmations, the algorithm was not reliable in identifying complex content such as change and sustain talk. Therefore, the involvement of human-based problem identification and supervision is still necessary for more complex issues where algorithms fail. However, given that mistakes like the drift in conversational focus and advice giving, which are commonly committed by novices, could be reliably identified automatically, these algorithms could serve as the first layer of solution, saving human resources for more complicated scenarios.

Interventions during sessions can have immediate impact on the helper's behavior and potential to influence a session's outcome. However, research is still needed to understand whether information overload and other problems will prevent helpers from responding appropriately to this feedback. In addition, feedback algorithms will contain both recognition errors (e.g., is an utterance really an

Proc. ACM Hum.-Comput. Interact., Vol. 5, No. CSCW2, Article 366. Publication date: October 2021. 
affirmation) and conversational errors (e.g., is the helper affirming the right activity). As a result, machine-learning-based approaches should be designed as suggestions and nudges, providing information that might not be otherwise visible, and never limit a helper's freedom in conducting the conversation. Therefore, it is important in design to emphasis user choice and frame the intervention as optional information to consider, instead of objective truth in order to prevent user's over-reliance on the algorithm instead of their own judgment [34].

\subsection{Post-session: reflection and feedback}

An additional opportunity for support happens after a support session is concluded. After a session is complete, the session transcript provides the opportunities for helpers to analyze their behavior, reflecting on what went well or poorly, and potentially to identify areas for improvement. As suggested in the design implication sessions previously, feedback from either the helper themself, or from the community can provide opportunities for learning from one's own mistake that might not be apparent during the sessions. Prior literature has called attention to the role of reflection in a therapist's skill development: Bennett [12] proposed a model of counselor skill-development which emphasizes the importance of reflection, consistent with traditional learning science principles [15]. Research demonstrates that reflection is an effective tool for skill development after initial training $[21,63]$. These reflections take on different forms. For instance, [63] asked the participants to reflect on their skills by self-coding their conversation, identifying MI skills and elements. [21] however, used homework-like questions asking participants to answer questions on their performance, write about their experience and come up with alternative scenarios. These are all potential designs that amateur supporters can also benefit from.

Although reflection is valuable, effective reflection is challenging when problem diagnosis relies on recall. Recalling thoughts and behaviors post-hoc is often inaccurate [64]. We believe that a more unified approach that connects the in-session elements with post-session reflection can substantially strengthen the reflection process. During the session itself, participants can mark critical events worthy of reflection (e.g., when an open-ended question failed to draw out an appropriate response). Support for this approach can be seen in [54] where the authors allowed designers to mark significant moments in a design session in real-time to capture and record spontaneous moments and insights and showed improved post-session knowledge consolidation. In addition, this process is also well-aligned with the in-session support that we proposed above: mistakes identified by machine-learning algorithm can also be used as places for reflection postsession, allowing helpers to analyze in-depth what mistakes were made and how they could be corrected. Moreover, similar to our prior suggestion, community-based reflection and feedback should also be considered. The strength of a community of supporters is that it has supporters with different levels of experience, skills, and expertise. Community feedback and peer advice often supports learning and enhance engagement and social interactions [72]. Using the experts in the community to provide feedback and help novice supporters reflect by reviewing session notes or questions submitted by novice helpers could provide a different perspective and guidance that novice helpers might themselves lack initially.

Lastly, post-session reflections could help novice supporters generate insights that might go beyond their training. Our training provided the helpers with a few basics conversation skills. Although some of the participants could not properly digest the skills, such as reflection, or employed them awkwardly, the majority were able to effectively adapt and extrapolate beyond what was taught. They were able to use their inherent "people skills" that people naturally use in regular interactions, such as expressing empathy and conducting small talk. These people skills allowed helpers to extrapolate the MI skills beyond their simple definitions. Helpers combined their pre-existing conversational skills with the MI skills they received during training and adapted the 
MI skills to the conversation goals they wanted to achieve. For instance, participants used obvious open-ended questions to point out the benefits of change as well as for their conventional purpose of finding out more about the clients and their problems. Post-session reflection could help people understand better how and when to use their pre-existing skills to achieve therapeutic goals.

We believe that the unified and systematic approach we have just described will help novices more quickly become better helpers. As we discussed, there is a clear connection between the scaffolding provided during these stages: preparation allows helpers to plan how the session should go, real-time support provides immediate feedback on these planned actions and a chance to correct mistakes, and post-session reviews provide an opportunity to look at the conversational the actions, successes, and mistakes and develop insight can be used to improve future sessions.

\section{LIMITATIONS}

One limitation of our study is that it was carried out in a controlled environment with a fixed topic, rather than within an existing peer support platform. Therefore, it is possible that we did not capture challenges that rise in more realistic environments. Participants focused on procrastination because it is a problem many people have, but it is only one of the many that get discussed on online support platforms. In addition, the types of people we recruited and their motives for participating undoubtedly differ from the populations who use online support platforms like 7 Cups. However, we believe that by fixing the topic, we reduced individually differences and were more able to identify consistent strategies and challenges new novice helpers face. A second limitation is that we have no objective measure of the success of the conversations. The data consist of observations of participants' ability to employ the skills they were taught and their reports of problems they were having. However, we do not know whether the application of these skills allowed the helpers to more accurately identify client's problems or the change their behavior. Lastly, the research focuses mainly on the helpers and their actions and experiences. Although the client's experience is also important, we also believe that by scaffolding an experience to support the helpers, clients would indirectly benefit, but we have no direct evidence to support this assumption.

\section{CONCLUSIONS AND FUTURE RESEARCH}

In this paper, we provided novice online peer-supporters a modicum of training on motivational interviewing skills and examined qualitatively the experiences using them. We identified a variety of strategies that they employed in their support conversation with clients. In order to analyze clients' problems, helpers asked questions and used reflections to get clients to elaborate, but helpers faced challenges in asking the right questions and using reflections properly. They also faced substantial cognitive load when using the text-based platform. To build rapport, helpers frequently employed small talk and tried to show empathy for the client. However, they faced challenges with awkward initial interactions with the client, adjusting to their role as a helper, and conveying non-verbal cues through the text-based channel. To evoke commitment, helpers tried to lead the conversation towards change, but sometimes lost focus and gave too much advice; they also felt inadequate about their own abilities. Lastly, helpers tried to empower the client with affirmation but faced the challenge of affirming the right element and feeling sincere. We discussed design implications of these challenges and examined how these design elements can work together to systematically scaffold the experience for novice supporters. In future studies, we aim to examine these findings in context by expanding the topics as well as confirming our findings with real-life supporters. We also aim to design services, interventions, and interfaces based on these findings and empirically verify their impact on helpers' performances. 


\section{REFERENCES}

[1] Steven J Ackerman and Mark J Hilsenroth. 2003. A review of therapist characteristics and techniques positively impacting the therapeutic alliance. Clinical psychology review 23, 1 (2003), 1-33.

[2] Anna Liisa Aho, Marja-Terttu Tarkka, Päivi Åstedt-Kurki, Leena Sorvari, and Marja Kaunonen. 2011. Evaluating a bereavement follow-up intervention for grieving fathers and their experiences of support after the death of a child-A pilot study. Death studies 35, 10 (2011), 879-904.

[3] B Alex Matthews, Frank Baker, Danette M Hann, Maxine Denniston, and Tenbroeck G Smith. 2002. Health status and life satisfaction among breast cancer survivor peer support volunteers. Psycho-Oncology: fournal of the Psychological, Social and Behavioral Dimensions of Cancer 11, 3 (2002), 199-211.

[4] Kathina Ali, Louise Farrer, Amelia Gulliver, and Kathleen M Griffiths. 2015. Online peer-to-peer support for young people with mental health problems: a systematic review. FMIR mental health 2, 2 (2015), e19.

[5] Yair Amichai-Hamburger, Anat Brunstein Klomek, Doron Friedman, Oren Zuckerman, and Tal Shani-Sherman. 2014. The future of online therapy. Computers in Human Behavior 41 (2014), 288-294.

[6] Cristelle T Audet. 2011. Client perspectives of therapist self-disclosure: Violating boundaries or removing barriers? Counselling Psychology Quarterly 24, 2 (2011), 85-100.

[7] Albert Bandura. 1977. Self-efficacy: toward a unifying theory of behavioral change. Psychological review 84, 2 (1977), 191.

[8] Anika Batenburg and Enny Das. 2014. Emotional approach coping and the effects of online peer-led support group participation among patients with breast cancer: a longitudinal study. fournal of medical Internet research 16, 11 (2014), e256.

[9] Amit Baumel. 2015. Online emotional support delivered by trained volunteers: users' satisfaction and their perception of the service compared to psychotherapy. Journal of Mental Health 24, 5 (2015), 313-320.

[10] Amit Baumel and Stephen M. Schueller. 2016. Adjusting an Available Online Peer Support Platform in a Program to Supplement the Treatment of Perinatal Depression and Anxiety. FMIR Mental Health 3, 1 (2016), e11. https: //doi.org/10.2196/mental.5335 Company: JMIR Mental Health Distributor: JMIR Mental Health Institution: JMIR Mental Health Label: JMIR Mental Health Publisher: JMIR Publications Inc., Toronto, Canada.

[11] Judith S Beck and Aaron T Beck. 1995. Cognitive therapy: Basics and beyond. Number Sirsi) i9780898628470. Guilford press New York.

[12] James Bennett-Levy. 2006. Therapist skills: A cognitive model of their acquisition and refinement. Behavioural and Cognitive Psychotherapy 34, 1 (2006), 57-78.

[13] James Bennett-Levy, Richard Thwaites, Beverly Haarhoff, and Helen Perry. 2014. Experiencing CBT from the inside out: A self-practice/self-reflection workbook for therapists. Guilford Publications.

[14] Richard J Bischoff. 1997. Themes in therapist development during the first three months of clinical experience. Contemporary Family Therapy 19, 4 (1997), 563-580.

[15] Evelyn M Boyd and Ann W Fales. 1983. Reflective learning: Key to learning from experience. fournal of humanistic psychology 23, 2 (1983), 99-117.

[16] Doğan Can, Rebeca A Marín, Panayiotis G Georgiou, Zac E Imel, David C Atkins, and Shrikanth S Narayanan. 2016. "It sounds like...”: A natural language processing approach to detecting counselor reflections in motivational interviewing. Journal of counseling psychology 63, 3 (2016), 343.

[17] Arik Cheshin, Anat Rafaeli, and Nathan Bos. 2011. Anger and happiness in virtual teams: Emotional influences of text and behavior on others' affect in the absence of non-verbal cues. Organizational behavior and human decision processes 116, 1 (2011), 2-16.

[18] Matthew Chinman, Preethy George, Richard H Dougherty, Allen S Daniels, Sushmita Shoma Ghose, Anita Swift, and Miriam E Delphin-Rittmon. 2014. Peer support services for individuals with serious mental illnesses: assessing the evidence. Psychiatric Services 65, 4 (2014), 429-441.

[19] KR Collie, Dan Mitchell, and Lawrence Murphy. 2000. Skills for online counseling: Maximum impact at minimum bandwidth. Cybercounseling and cyberlearning: Strategies and resources for the millennium. Alexandria, VA: American Counseling Association (2000).

[20] Larry Davidson, Matthew Chinman, David Sells, and Michael Rowe. 2006. Peer support among adults with serious mental illness: a report from the field. Schizophrenia bulletin 32, 3 (2006), 443-450.

[21] Melanie L Davis, Richard Thwaites, Mark H Freeston, and James Bennett-Levy. 2015. A measurable impact of a self-practice/self-reflection programme on the therapeutic skills of experienced cognitive-behavioural therapists. Clinical Psychology \& Psychotherapy 22, 2 (2015), 176-184.

[22] Alyssa R Dietz and Michael E Dunn. 2014. The use of motivational interviewing in conjunction with adapted dialectical behavior therapy to treat synthetic cannabis use disorder. Clinical Case Studies 13, 6 (2014), 455-471.

[23] Mitchell Dowling and Debra Rickwood. 2013. Online counseling and therapy for mental health problems: A systematic review of individual synchronous interventions using chat. Journal of Technology in Human Services 31, 1 (2013), 1-21. 
[24] Louise A Ellis, Philippa Collin, Patrick J Hurley, Tracey A Davenport, Jane M Burns, and Ian B Hickie. 2013. Young men's attitudes and behaviour in relation to mental health and technology: implications for the development of online mental health services. BMC psychiatry 13, 1 (2013), 119.

[25] Norman B Epstein and Donald H Baucom. 2002. Enhanced cognitive-behavioral therapy for couples: A contextual approach. American Psychological Association.

[26] Lin Fang, Sarah Tarshis, Lauren McInroy, and Faye Mishna. 2018. Undergraduate student experiences with text-based online counselling. The British fournal of Social Work 48, 6 (2018), 1774-1790.

[27] Angela Cora Garcia and Jennifer Baker Jacobs. 1999. The eyes of the beholder: Understanding the turn-taking system in quasi-synchronous computer-mediated communication. Research on language and social interaction 32, 4 (1999), 337-367.

[28] Kathleen Margaret Griffiths, Alison L Calear, and Michelle Banfield. 2009. Systematic review on Internet Support Groups (ISGs) and depression (1): Do ISGs reduce depressive symptoms? fournal of medical Internet research 11, 3 (2009), e40.

[29] Kathleen M. Griffiths, Andrew J. Mackinnon, Dimity A. Crisp, Helen Christensen, Kylie Bennett, and Louise Farrer. 2012. The Effectiveness of an Online Support Group for Members of the Community with Depression: A Randomised Controlled Trial. PLOS ONE 7, 12 (Dec. 2012), e53244. https://doi.org/10.1371/journal.pone.0053244 Publisher: Public Library of Science.

[30] Rosanna E Guadagno, Kimberly R Swinth, and Jim Blascovich. 2011. Social evaluations of embodied agents and avatars. Computers in Human Behavior 27, 6 (2011), 2380-2385.

[31] Danielle N Gunraj, April M Drumm-Hewitt, Erica M Dashow, Sri Siddhi N Upadhyay, and Celia M Klin. 2016. Texting insincerely: The role of the period in text messaging. Computers in Human Behavior 55 (2016), 1067-1075.

[32] Terry Hanley and D Reynolds. 2009. Counselling psychology and the internet: A review of the quantitative research into online outcomes and alliances within text-based therapy. Counselling Psychology Review 24, 2 (2009), 4-13.

[33] Nick Heather and Tim Stockwell. 2004. The Essential Handbook of Treatment and Prevention of Alcohol Problems. John Wiley \& Sons. Google-Books-ID: 54yUzyDiTJ0C.

[34] Victoria Hollis, Alon Pekurovsky, Eunika Wu, and Steve Whittaker. 2018. On being told how we feel: how algorithmic sensor feedback influences emotion perception. Proceedings of the ACM on Interactive, Mobile, Wearable and Ubiquitous Technologies 2, 3 (2018), 1-31.

[35] James Ikonomopoulos, Javier Cavazos Vela, Wayne D Smith, and Julia Dell'Aquila. 2016. Examining the practicum experience to increase counseling students' self-efficacy. The Professional Counselor 6, 2 (2016), 161.

[36] Chang Min Kim, Hyeon-Beom Yi, Ji-Won Nam, and Geehyuk Lee. 2017. Applying Real-Time Text on Instant Messaging for a Rapid and Enriched Conversation Experience. In Proceedings of the 2017 Conference on Designing Interactive Systems. 625-629.

[37] Taemie Kim, Agnes Chang, Lindsey Holland, and Alex Sandy Pentland. 2008. Meeting mediator: enhancing group collaborationusing sociometric feedback. In Proceedings of the 2008 ACM conference on Computer supported cooperative work. 457-466.

[38] Christine A Limbers, Erlanger A Turner, and James W Varni. 2008. Promoting healthy lifestyles: Behavior modification and motivational interviewing in the treatment of childhood obesity. Journal of Clinical Lipidology 2, 3 (2008), 169-178.

[39] Shery Mead, David Hilton, and Laurie Curtis. 2001. Peer support: A theoretical perspective. Psychiatric rehabilitation journal 25, 2 (2001), 134.

[40] Belinda Melling and Terry Houguet-Pincham. 2011. Online peer support for individuals with depression: A summary of current research and future considerations. Psychiatric rehabilitation journal 34, 3 (2011), 252.

[41] William R Miller. 1996. Motivational interviewing: research, practice, and puzzles. Addictive behaviors 21, 6 (1996), 835-842.

[42] William R. Miller and Stephen Rollnick. 2012. Motivational Interviewing: Helping People Change. Guilford Press.

[43] William R Miller and Gary S Rose. 2009. Toward a theory of motivational interviewing. American psychologist 64, 6 (2009), 527.

[44] Anne L Mounsey, Viktor Bovbjerg, Laura White, and John Gazewood. 2006. Do students develop better motivational interviewing skills through role-play with standardised patients or with student colleagues? Medical education 40, 8 (2006), 775-780.

[45] Theresa B Moyers, Tim Martin, Jennifer K Manuel, Stacey ML Hendrickson, and William R Miller. 2005. Assessing competence in the use of motivational interviewing. Fournal of substance abuse treatment 28, 1 (2005), 19-26.

[46] David Myers and Jeffrey A Hayes. 2006. Effects of therapist general self-disclosure and countertransference disclosure on ratings of the therapist and session. Psychotherapy: Theory, Research, Practice, Training 43, 2 (2006), 173.

[47] Keris Myrick and Paolo del Vecchio. 2016. Peer support services in the behavioral healthcare workforce: State of the field. Psychiatric rehabilitation journal 39, 3 (2016), 197. 
[48] Mageshprasath Nagarajan and S Yuvaraj. 2019. Mental health counsellors' perceptions on use of technology in counselling. Current Psychology (2019), 1-7.

[49] JA Naslund, KA Aschbrenner, LA Marsch, and SJ Bartels. 2016. The future of mental health care: peer-to-peer support and social media. Epidemiology and psychiatric sciences 25, 2 (2016), 113-122.

[50] Cameron Newton, Karen Becker, and Sarah Bell. 2014. Learning and development opportunities as a tool for the retention of volunteers: a motivational perspective. Human Resource Management fournal 24, 4 (2014), 514-530. https://doi.org/10.1111/1748-8583.12040_eprint: https://onlinelibrary.wiley.com/doi/pdf/10.1111/1748-8583.12040.

[51] 7 Cups of Tea. 2020 (accessed September 17, 2020). 7 Cups of Tea. https://www.7cups.com/

[52] Kathleen O’Leary, Stephen M Schueller, Jacob O Wobbrock, and Wanda Pratt. 2018. "Suddenly, we got to become therapists for each other" Designing Peer Support Chats for Mental Health. In Proceedings of the 2018 CHI conference on human factors in computing systems. 1-14.

[53] Zoë D Peterson. 2002. More than a mirror: The ethics of therapist self-disclosure. Psychotherapy: Theory, Research, Practice, Training 39, 1 (2002), 21.

[54] Søren Rasmussen, Jeanette Falk Olesen, and Kim Halskov. 2019. Co-notate: Exploring Real-time Annotations to Capture Situational Design Knowledge. In Proceedings of the 2019 on Designing Interactive Systems Conference. 161-172.

[55] Karen L Rebeiro Gruhl, Sara LaCarte, and Shana Calixte. 2016. Authentic peer support work: challenges and opportunities for an evolving occupation. fournal of mental health 25, 1 (2016), 78-86.

[56] Daniela Retelny, Sébastien Robaszkiewicz, Alexandra To, Walter S Lasecki, Jay Patel, Negar Rahmati, Tulsee Doshi, Melissa Valentine, and Michael S Bernstein. 2014. Expert crowdsourcing with flash teams. In Proceedings of the 27th annual ACM symposium on User interface software and technology. 75-85.

[57] Derek Richards and Noemi Viganó. 2013. Online counseling: A narrative and critical review of the literature. fournal of clinical psychology 69, 9 (2013), 994-1011.

[58] Matthew Robison, Nash Unsworth, and Gene Brewer. 2020. Examining the effects of goal-setting, feedback, and incentives on sustained attention. (2020).

[59] Stephen Rollnick, William R Miller, and Christopher Butler. 2008. Motivational interviewing in health care: helping patients change behavior. Guilford Press.

[60] Barbara Olasov Rothbaum, Elizabeth A Meadows, Patricia Resick, and David W Foy. 2000. Cognitive-behavioral therapy. (2000).

[61] Sune Rubak, Annelli Sandbæk, Torsten Lauritzen, and Bo Christensen. 2005. Motivational interviewing: a systematic review and meta-analysis. British journal of general practice 55, 513 (2005), 305-312.

[62] Saruta Saengtipbovorn. 2017. Efficacy of motivational interviewing in conjunction with caries risk assessment (MICRA) programmes in improving the dental health status of preschool children: a randomised controlled trial. Oral Heal Prev Dent 15 (2017), 123-9.

[63] AM Schoo, S Lawn, E Rudnik, and John Charles Litt. 2015. Teaching health science students foundation motivational interviewing skills: use of motivational interviewing treatment integrity and self-reflection to approach transformative learning. BMC medical education 15, 1 (2015), 1-10.

[64] Saul Shiffman, Michael Hufford, Mary Hickcox, Jean A Paty, Maryann Gnys, and Jon D Kassel. 1997. Remember that? A comparison of real-time versus retrospective recall of smoking lapses. Fournal of consulting and clinical psychology 65, 2 (1997), 292.

[65] Andrea Galiette Skoglund. 2006. Do not forget about your volunteers: A qualitative analysis of factors influencing volunteer turnover. Health and Social work 31, 3 (2006), 217.

[66] Jacob Solomon, Mark Newman, and Stephanie Teasley. 2010. Speaking through text: the influence of real-time text on discourse and usability in IM. In Proceedings of the 16th ACM international conference on supporting group work 197-200

[67] Phyllis Solomon. 2004. Peer support/peer provided services underlying processes, benefits, and critical ingredients. Psychiatric rehabilitation journal 27, 4 (2004), 392.

[68] Anselm Strauss and Juliet Corbin. 1990. Basics of qualitative research. Sage publications.

[69] John Suler. 2004. The online disinhibition effect. Cyberpsychology \& behavior 7, 3 (2004), 321-326.

[70] Soo Yin Tan and Chih Chin Chou. 2018. Supervision effects on self-efficacy, competency, and job involvement of school counsellors. Journal of Psychologists and Counsellors in Schools 28, 1 (2018), 18.

[71] Michael Tanana, Kevin A Hallgren, Zac E Imel, David C Atkins, and Vivek Srikumar. 2016. A comparison of natural language processing methods for automated coding of motivational interviewing. Journal of substance abuse treatment 65 (2016), 43-50.

[72] Brian Thoms. 2011. A dynamic social feedback system to support learning and social interaction in higher education IEEE Transactions on Learning Technologies 4, 4 (2011), 340-352.

[73] Richard Thwaites, James Bennett-Levy, Melanie Davis, and Anna Chaddock. 2014. Using self-practice and self-reflection (SP/SR) to enhance CBT competence and metacompetence. (2014). 
[74] Heather Trepal, Shane Haberstroh, Thelma Duffey, and Marcheta Evans. 2007. Considerations and strategies for teaching online counseling skills: Establishing relationships in cyberspace. Counselor Education and Supervision 46, 4 (2007), 266-279.

[75] Carolyn Turvey, Mirean Coleman, Oran Dennison, Kenneth Drude, Mark Goldenson, Phil Hirsch, Robert Jueneman, Greg M Kramer, David D Luxton, Marlene M Maheu, et al. 2013. ATA practice guidelines for video-based online mental health services. Telemedicine and e-Health 19, 9 (2013), 722-730.

[76] Jane Ussher, Laura Kirsten, Phyllis Butow, and Mirjana Sandoval. 2006. What do cancer support groups provide which other supportive relationships do not? The experience of peer support groups for people with cancer. Social science \& medicine 62, 10 (2006), 2565-2576.

[77] Patti M Valkenburg and Jochen Peter. 2011. Online communication among adolescents: An integrated model of its attraction, opportunities, and risks. Journal of adolescent health 48, 2 (2011), 121-127.

[78] Sarah Theres Völkel, Daniel Buschek, Jelena Pranjic, and Heinrich Hussmann. 2019. Understanding emoji interpretation through user personality and message context. In Proceedings of the 21st International Conference on Human-Computer Interaction with Mobile Devices and Services. 1-12.

[79] Gill Walker and Wendy Bryant. 2013. Peer support in adult mental health services: a metasynthesis of qualitative findings. Psychiatric Rehabilitation fournal 36, 1 (2013), 28.

[80] Joseph B Walther, Brandon Van Der Heide, Artemio Ramirez, Judee K Burgoon, and Jorge Peña. 2015. Interpersonal and hyperpersonal dimensions of computer-mediated communication. The handbook of the psychology of communication technology 1 (2015), 22.

[81] Yi-Chia Wang, Robert E Kraut, and John M Levine. 2015. Eliciting and receiving online support: using computer-aided content analysis to examine the dynamics of online social support. fournal of medical Internet research 17, 4 (2015), e99.

[82] Mitch Wolden, Brittany Anderson, and Chris Ray. 2019. Changes in perceived self-efficacy of physical therapist students following a pediatric experiential learning opportunity. Pediatric Physical Therapy 31, 1 (2019), 115-120.

Received October 2020; revised April 2021; accepted July 2021 